\title{
Myofibroblasts in hollow visceral myopathy: the origin of gastrointestinal fibrosis?
}

\author{
J E Martin, M Benson, M Swash, V Salih, A Gray
}

\begin{abstract}
A patient with hollow visceral myopathy is reported in whom light microscopical studies of the small and large intestine showed typical features of degeneration, thinning, and fibrous replacement of smooth muscle of the gastrointestinal tract. Electron microscopy showed a striking increase in collagen with minimal fibroblast proliferation. Smooth muscle fibres had a range of ultrastructural abnormalities including myofilament disarray, electron lucency of the cytoplasm, and proliferation of the endoplasmic reticulum. Some fibres seemed to have typical ultrastructural characteristics of myofibroblasts, and others to be transition forms between typical smooth muscle cells and typical myofibroblasts. It seems likely that the fibrosis typical of this disorder has its origin in the transformation of smooth muscle fibres from a purely contractile to a myofibroblast collagen synthetic phenotype.
\end{abstract}

(Gut 1993; 34: 999-1001)

M Swash

V Salih

A Gray

Department of

Gastroenterology, Royal

London Hospital,

Whitechapel, London

M Benson

Correspondence to:

Dr J E Martin, Department of

Neuropathology, The

Institute of Pathology, The

Institute of Pathology, The

Royal London Hospital

E1 1BB.

Accepted for publication

18 November 1992
We report detailed ultrastructural studies on tissue from a patient with visceral myopathy in whom there were prominent alterations in smooth muscle fibres of the muscularis propria, which included the presence of cells with the typical appearance of myofibroblasts. It is suggested that the fibrosis seen in this disorder has its origin in the transformation of smooth muscle fibres from a purely contractile to a myofibroblast collagen synthetic phenotype.

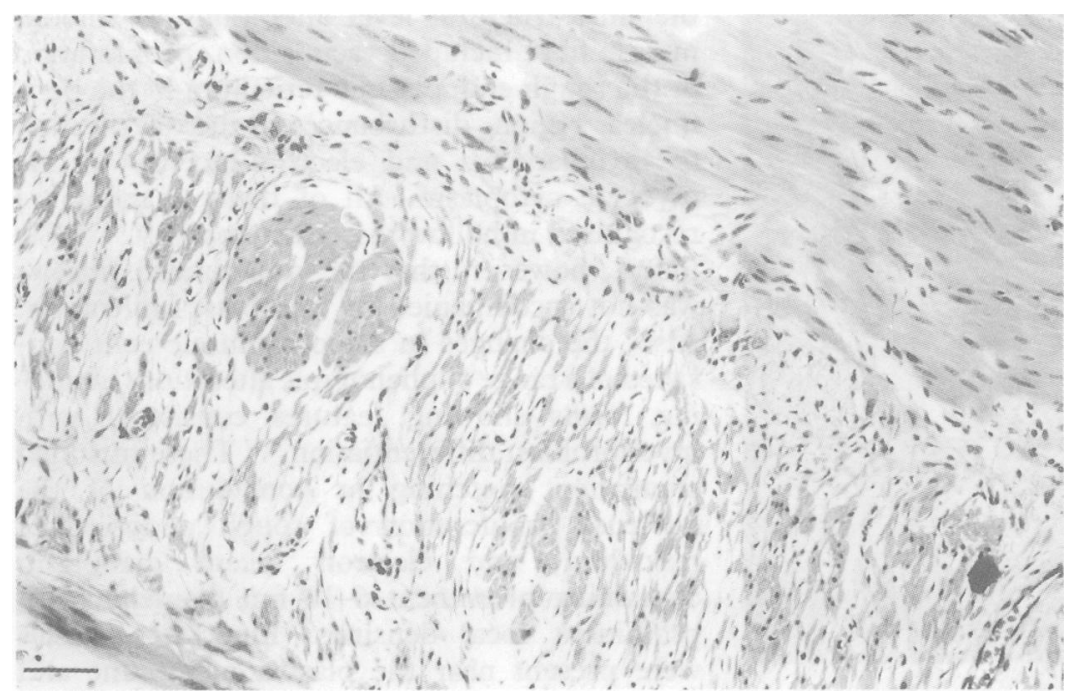

Figure 1: Low power light micrograph of terminal ileum showing loss and degeneration of smooth muscle cells with fibrosis particularly affecting the external layer of the muscularis propria. Haematoxylin and eosin; bar $=100 \mu \mathrm{m}$

\section{Case report}

A 14 year old girl presented with constipation, intermittent abdominal pain, and vomiting. She underwent appendicetomy at age 17 . She continued to experience abdominal pain and at age 18 was admitted with absolute constipation and intestinal obstruction. At laparotomy she was noted to have thickened bowel loops and a thickened dilated colon. No structural obstruction was noted. Investigation over the next two years showed intestinal hypomotility, with formal small bowel motility studies showing uncoordinated phase 3 propagation. She had difficulty with micturition, but no haematuria or dysuria. No other abnormalities were present on examination or investigation. At age 20 she became pregnant and the pregnancy was complicated by episodes of small and large bowel obstruction. A colostomy was performed in an attempt to relieve her large bowel symptoms, and subsequently closed. The labour was uneventful and the child, now aged 10, shows normal development.

During the next 10 years the patient suffered bouts of subacute obstruction and frequent faecal impaction with admissions for abdominal pain, absolute constipation, and vomiting, necessitating left extended hemicolectomy at the age of 22. At age 29 she underwent successful parathyroidectomy for primary hyperparathyroidism with nodular hyperplasia. No other endocrine abnormalities were present and calcium concentrations returned to normal after surgery. Her intestinal symptoms progressed and she vomited copious amounts of fluid every two to three hours. She had no appetite and her food intake declined to zero. A central venous line was inserted for home total parenteral nutrition. By the age of 30 she was still maintained on home total parenteral nutrition, and continued to vomit fluid. She also had gross abdominal distention and absolute constipation. She underwent further ileal resection to reduce her distention and tubal ligation for sterilisation.

Resection specimens of colon and ileum from the abdominal operations at ages 22 and 30 were studied histologically. Specimens were taken fresh and samples fixed in $2.5 \%$ glutaraldehyde for transmission electron microscopy and $10 \%$ formol saline for light microscopy. Samples from each specimen of bowel were taken at $5-10 \mathrm{~cm}$ intervals. All specimens of colon and ileum showed similar features. At light microscopy (haematoxylin and eosin, and elastic Van Gieson stains) there was thickening of the bowel wall by fibrous tissue with abnormalities of the muscularis propria, especially the external longitudinal layer (Fig 1). This showed loss of smooth muscle fibres, with remaining fibres showing 


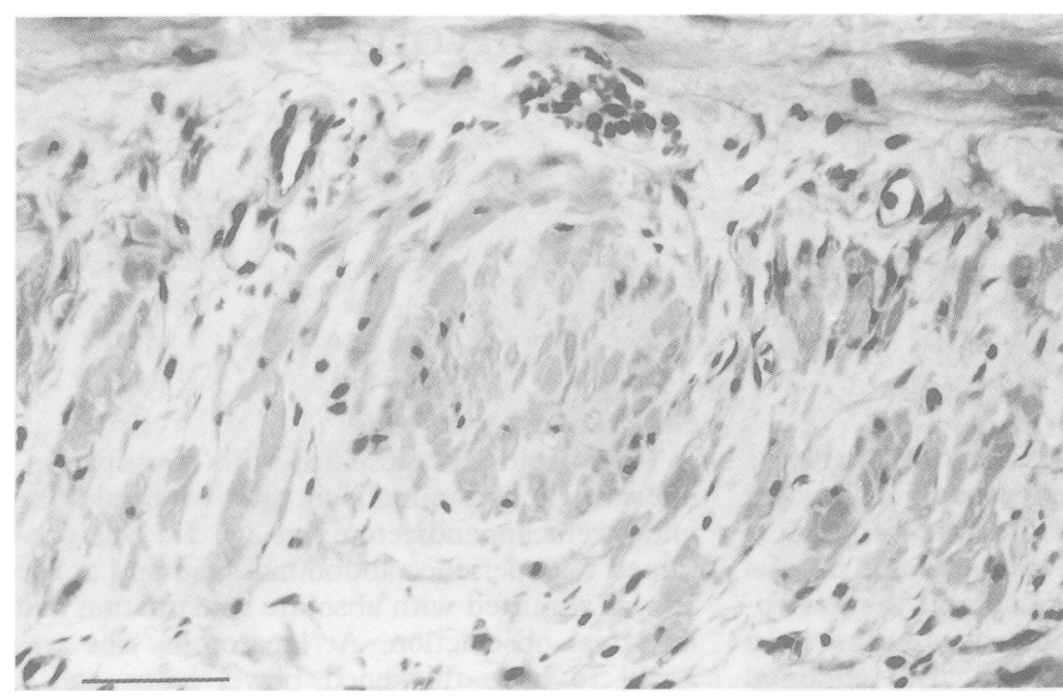

Figure 2: High power light micrograph showing fibrosis and smooth muscle degeneration with vacuolation and hypertrophy in the external layer of the muscularis propria. Haematoxylin and eosin; bar $=100 \mu \mathrm{m}$.

hypertrophy, vacuolation, or degenerative features (Fig 2). Mucopolysaccharide and amyloid deposition was not detected with Alcian blue-periodic acid Schiff and Congo red stains. The submucosal and myenteric neural plexuses seemed normal in number and morphology with no intraneuronal inclusions or vacuolation present. Staining with neuron specific enolase and neurofilament antibodies (Sigma, UK) by indirect immunoperoxidase methods showed no abnormalities of distribution or morphology of neuronal cell bodies or axons.

Ultrastructural studies showed increased collagen in the muscularis propria with alterations in smooth muscle fibres including elongation, cytoplasmic vacuolation, proliferation of rough endoplasmic reticulum, myofilament disarray with increased lucency of myocyte cytoplasm, and prominent focal densities. Fibroblast infiltration was not prominent, with occasional fibroblast-like cells seen but not in abnormal

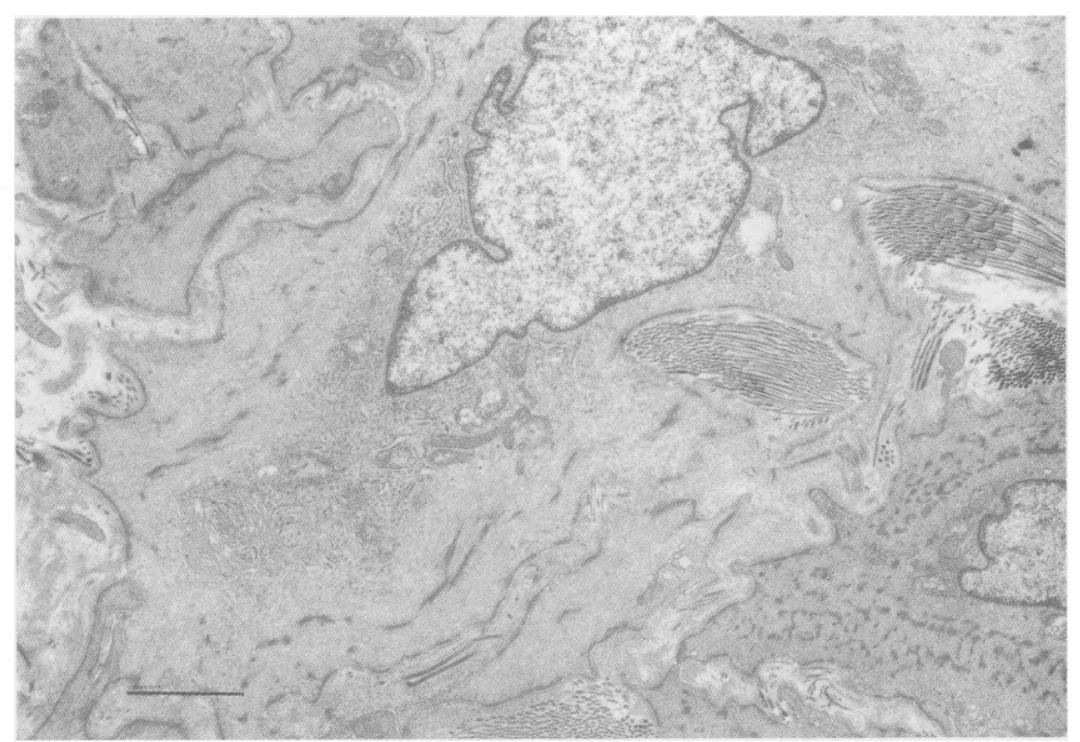

Figure 3: Electron micrograph showing typical myofibroblast from the external layer of the muscularis propria of the transverse colon. Note extracellular collagen deposition, notched nuclei, proliferation of endoplasmic reticulum, electron lucency of the cytoplasm, and prominen focal densities. Micropinocytic vesicles are also visible. Bar $=2 \mu \mathrm{m}$. numbers (Figs 3, 4). All nerve fibres and terminals present seemed normal in number and morphology. Similar ultrastructural features were present in the ileum and colon, with the most noticeable abnormalities present in the muscularis propria.

Light microscopical studies of smooth muscle of the fallopian tubes showed no histological abnormalities. Sections of the appendix and bladder biopsies were not available.

\section{Discussion}

Primary chronic intestinal pseudo-obstruction occurs without underlying systemic disease. ${ }^{12}$ This syndrome is characterised clinically by abnormalities of gastrointestinal and, in some cases, bladder motility. ${ }^{34}$ When thought to involve abnormalities of smooth muscle without abnormalities in myenteric neurons the syndrome is termed hollow visceral myopathy. ${ }^{3}$ This is considered to be the commonest cause of chronic primary intestinal pseudo-obstruction. Different patterns of clinical involvement with genetic transmission ${ }^{467}$ or sporadic occurrence ${ }^{8}$ are recognised. The histopathological findings are similar in all types. ${ }^{1-35-8}$ At light microscopy smooth muscle layers show fibrosis with vacuolar and other degenerative changes in smooth muscle fibres in the circular and longitudinal muscle layers. Ultrastructural abnormalities in smooth muscle fibres have been recognised, including myocyte damage with perinuclear vacuolation, disorientation and dissolution of myofilaments, electron lucency of the cytoplasm, and swelling of mitochondria. ${ }^{1358}$ The origin of the fibrosis in this condition is unclear. Our findings suggest an explanation.

The typical clinical and histological features of hollow visceral myopathy, including pseudoobstruction of the bowel with fibrosis, thinning, and vacuolation of the smooth muscle of the muscularis propria were present in our case. It is likely that our case represents the sporadic type of the disorder, in the absence of any family history. The familial form cannot be excluded, however, without full investigation of other family members, which is not possible here. At the ultrastructural level alterations of smooth muscle fibre included vacuolation, proliferation of the rough endoplasmic reticulum in the perinuclear region, disturbances in the distribution of myofilaments and electron-lucency of the myocyte cytoplasm. All of these changes are recognised in hollow visceral myopathy. ${ }^{1358} \mathrm{We}$ found, however, that the pronounced fibrosis was not accompanied by fibroblast infiltration. Also, the changes in smooth muscle cells consisted of a range of phenotypic alterations including forms showing features consistent with myofibroblast differentiation. ${ }^{9-12}$ These included elongation, notching or convolution of the nucleus, proliferation of rough endoplasmic reticulum, and electron lucent cytoplasm containing prominent 6-10 nm filaments with prominent focal densities. Pinocytic vesicles were present near the plasma membrane and basement membrane was present around these cells. Such myofibroblast type cells were focally surrounded by mature collagen fibres. 


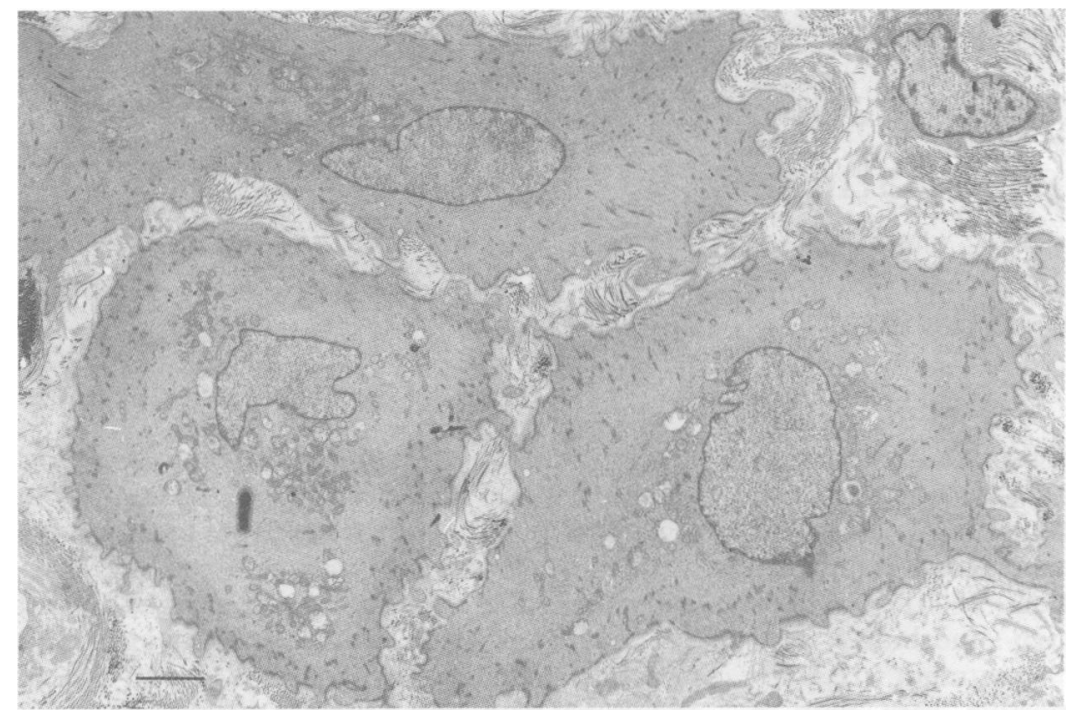

Figure 4: Electron micrograph showing smooth muscle cells with features of myofibroblast differentiation from the external layer of the muscularis propria of the descending colon. Note extracellular collagen deposition, notched nuclei, proliferation of endoplasmic reticulum, focal electron lucency of the cytoplasm, and prominent focal densities. Micropinocytic vesicles are also visible. Bar=2 $\mathrm{\mu m}$. vation of the bowel seems morphologically normal and the response of the smooth muscle seems to follow a recognised pathophysiological response. ${ }^{22-24}$ The precise stimulus to such alteration and the reversibility of the change, however, is not clear.

JEM is a Wellcome Trust Research Fellow and holds the Gillson Scholarship in Pathology of the Worshipful Society of Apothecaries. Our work is supported by the Motor Neuron Disease Association of Great Britain.

1 Mitros FA, Schuffler MD, Teja K, Anuras S. Pathologic features of familial visceral myopathy. Hum Pathol 1982; 13 825-33.

2 Christensen J, Dent J, Malagelada J-R, Wingate DL. Pseudoobstruction. Gastroenterology Int 1990; 3: 107-19.

3 Schuffler MD, Lowe MC, Bill AH. Studies of idiopathi intestinal pseudoobstruction. I. Hereditary hollow viscera myopathy: clinical and pathological studies. Gastroenterology 1977; 73: 327-38

4 Schuffler MD, Pope CE. Studies of idiopathic intestina pseudoobstruction. II. Hereditary hollow visceral myopathy: family studies. Gastroenterology 1977; 73: 33944.

5 Krishnamurthy S, Schuffler MD. Pathology of neuromuscula disorders of the small intestine and colon. Gastroenterology 1987; 93: 610-39.

6 Francois Y, Descos L, Berger F, Beurlet J, Cenni JC, MalletGuy Y, Vignal J. Rare type of visceral myopathy mimicking Guy Y, Vignal J. Rare type of visceral myopathy

7 Schuffler MD, Rohrmann CA, Chaffee RG, Brand DL, Delaney. JH, Young JH. Chronic intestinal pseudoobstruction. Medicine 1981; 60: 173-96.

8 Fitzgibbons PL, Chandrasoma PT. Familial viscera myopathy. Evidence of diffuse involvement of intestinal smooth muscle. Am $\mathcal{F}$ Surg Pathol 1987; 11: 846-54

9 Schurch W, Seemayer TA, Lagace R, Gabbiani G. The intermediate filament cytoskeleton of myofibroblasts: an immunofluorescence and ultrastructural study. Virchow Arch [A] 1984; 403: 323-36.

10 Richman PI, Tilly R, Jass JR, Bodmer W. Colonic pericryp sheath cells: characterisation of cell type with new monosheath cells: characterisation of cell type with
clonal antibody. F Clin Pathol 1987; 40: 593-600

11 Roche WR. Myofibroblasts. F Pathol $1990 ; 161: 281-2$.

12 Feigl W, Susani M, Ulrich W, Matejka M, Losert U, Sinzinge H. Organisation of experimental thrombosis by blood cells. Virchows Arch [A] 1985; 406: 133-48.

13 Gabbiani G, Ryan GB, Manjo G. Presence of modified fibroblasts in granulation tissue and their possible role in wound contraction. Experimentia 1971; 27: 549-50

14 Majno G, Gabbiani G, Hirschei BJ, Ryan GB, Statkov PR Contraction of granulation tissue in vitro: similarity to smooth muscle. Science $1971 ; 173$ : 548-50.

15 Gabbiani G, Hirschei BJ, Ryan GB, Statkov PR, Manjo G. Granulation tissue as a contractile organ. A study of structure and function. $\mathcal{F}$ Exp Med 1972; 135: 719-34.

16 Tomasek JJ, Schultz RJ, Episalla CW, Newman SA. The cytoskeleton and extracellular matrix of the Dupuytren's disease 'myofibroblast': an immunofluorescence study of a nonmuscle cell type. F Hand Surg [Am] 1986; 11: 365-71.

17 Adler KB, Low RB, Leslie KO, Mitchell J, Evans JN. Contractile cells in normal and fibrotic lung. Lab Invest Contractile cells

18 Skalli O, Schurch W, Seemayer T, Lagace R, Montadon D, Pittet B, Gabbiani G. Myofibroblasts from diverse pathologic settings are heterogenous in their content of actin isoforms and intermediate filament proteins. Lab Invest 1989; 60: 275-85.

19 Lipper S, Kahn LB, Reddick RL. The myofibroblast. Patho Annu 1980; 15: 409-41.

20 Balazs M, Kovacs $A$. The 'transitional' mucosa adjacent to large bowel carcinoma - electron microscopic features and myofibroblast reaction. Histopathology 1982; 6: 617-29.

21 Hwang WS, Kelly JK, Shaffer EA, Hershfield NB. Collagenous colitis: a disease of pericryptal fibroblast sheath? F Pathol 1986; 149: 33-40.

22 Ross R, Klebanoff SJ. Fine structural changes in uterine smooth muscle and fibroblasts in response to estrogen. $\mathcal{F} \mathrm{Cel}$ Biol 1967; 32: 155-60.

23 Ross R, Klebanoff SJ. The smooth muscle cell. I. In vivo synthesis of connective tissue proteins. 7 Cell Biol 1971; 50 $159-65$.

24 Schurch W, Seemayer TA, Gabbiani G. Myofibroblast. In Sternberg SS, ed. Histology for Pathologists. New York Raven Press, 1992: 109-44. 